\title{
Psychological Study of a Patient with COVID-19 at the Early Stage of the Epidemic
}

\author{
Xiaoqun Pang1*, Feifei Chen², Juan Wang³, Lili Li4 \\ ${ }^{1}$ Department of Infectious Diseases, The Third Affiliated Hospital of Sun Yat-sen University, Guangzhou, China \\ ${ }^{2}$ Department of Radiology, The Third Affiliated Hospital of Sun Yat-sen University, Guangzhou, China \\ ${ }^{3}$ Fever Clinic, The Third Affiliated Hospital of Sun Yat-sen University, Guangzhou, China \\ ${ }^{4}$ Department of Infectious Diseases, The Third Affiliated Hospital of Sun Yat-sen University, Guangzhou, China \\ Email: *973430644@qq.com, cfrg0545@163.com,1061613246@qq.com,22017377@qq.com
}

How to cite this paper: Pang, X.Q., Chen, F.F., Wang, J. and Li, L.L. (2021) Psychological Study of a Patient with COVID-19 at the Early Stage of the Epidemic. Open Journal of Nursing, 11, 801-807. https://doi.org/10.4236/ojn.2021.119067

Received: July 21, 2021

Accepted: September 24, 2021

Published: September 27, 2021

Copyright $\odot 2021$ by author(s) and Scientific Research Publishing Inc. This work is licensed under the Creative Commons Attribution International License (CC BY 4.0).

http://creativecommons.org/licenses/by/4.0/

\begin{abstract}
Coronavirus disease-2019 (COVID-19) caused by novel coronavirus 2019 (2019-nCoV) has led to $199,466,211$ confirmed cases, including 4,244,541 deaths by 6:44 pm CEST. This epidemic is now on the period of global outbreak, the control of COVID-19 has severely challenged the world. At the beginning of the outbreak, patients infected or suspected were observed and close contacts were isolated. The country delayed the resumption of work and school and all walks of life are seriously affected. All kinds of true and false information and rumours on the internet exist, aggravating people's anxiety and restlessness. These factors altogether often induce people to feel various negative emotions and psychological problems. In this paper, a patient with COVID-19 was examined through psychological dynamic observation at the beginning of the epidemic. It was found that in the early stage of the epidemic, due to the lack of clear treatment guidelines, the main treatment methods and psychological problems were the main reasons affecting the recovery of patients. Many uncertain factors, including individual and social factors and quarantine, worry about the prognosis, etc, resulting in anxiety, fear, unacceptance, insomnia, irritability and other pessimistic moods. After 16 days of symptomatic treatment, psychological counselling and adjustments in a timely manner, the patient eventually recovered and was discharged. The discussion of this case could serve as a reference for the treatment and rehabilitation of patients with COVID-19 in other countries and regions.
\end{abstract}

\section{Keywords}

COVID-19 Patients, Preliminary Stage of Epidemic, Psychological Observation Nursing 


\section{Introduction}

Coronavirus disease-2019 (COVID-19) caused by novel coronavirus 2019 (2019-nCoV) has led to 199,466,211 confirmed cases, including 4,244,541 deaths by 6:44 pm CEST [1]. The Coronavirus disease-2019 (COVID-19) epidemic has now on the period of the global outbreak, the control of COVID-19 epidemic has severely challenged the world. This disease could spread in the respiratory tract and by contact, with an incubation period of 1 - 14 days, most of which are 3 - 7 days. It is highly infectious, with recurrent fever, fatigue and dry cough as the main manifestations. Severe cases could be manifested as shortness of breath, dyspnoea and other respiratory symptoms and they further develop into respiratory distress, respiratory failure, multi-organ damage and even death [2]. This paper examined a patient with COVID-19 through psychological dynamic observation at the beginning of the epidemic. It was found that in the early stage of the epidemic, due to the lack of clear treatment guidelines, the main treatment methods and psychological problems were the main reasons affecting the recovery of patients. Due to many uncertain factors, including individual and social factors and quarantine, worry about the prognosis, etc, the patient generally appeared to have anxiety, fear, unacceptance, insomnia, irritability and other pessimistic moods. After 16 days of anti-infection antiviral, the combination of Chinese and Western medicine and other symptomatic treatment and psychological counseling, psychological counselling and adjustments in a timely manner, the patient eventually recovered and was discharged. The discussion of this case could serve as a reference for the treatment and rehabilitation of patients with COVID-19 in other countries and regions.

\section{Case Report}

The patient is a 37-year-old male from Guangzhou, Guangdong Province. Due to "fever with cough for 4 days", on January 22, 2020, an expert group consulted the emergency income isolation ward for treatment and the preliminary diagnosis was pneumonia (COVID-19). In the epidemiological history, the patient had general contact with someone (colleague) who returned to Guangzhou from high risk area on January 2 . The contact had no obvious symptoms of fever. The wife of the patient developed cough on the same day. Upon admission, the vital signs were as follows: $\mathrm{T}, 37.3^{\circ} \mathrm{C}$; $\mathrm{P}, 104$ times $/ \mathrm{min}$; $\mathrm{R}, 18$ times $/ \mathrm{min}$; and $\mathrm{BP}$, $131 / 65 \mathrm{mmHg}$. The other results were as follows: sanity, answered to the point; no rash; no lymph node enlargement; heart rate 104 times/min; uniform; no pathological murmur; pharyngeal hyperaemia; bilateral tonsil without swelling; slightly thick breath sounds in both lungs; no obvious dry and wet rales. The abdomen was soft and no tenderness nor rebound pain was observed. The liver and spleen were under the rib. The blood test results were as follows: WBC, 4.59 $\times 10^{9} / \mathrm{L}$; PLT, $136 \times 10^{9} / \mathrm{L}$; NEUT, 0.687; LYMPH, and $1 \times 10^{9} / \mathrm{L} . \mathrm{Mp}-\mathrm{ag}$ and rsv-ag were negative and influenza antigen $\mathrm{a} / \mathrm{b}$ was also negative. On thoracic $\mathrm{CT}$, double pulmonary infectious lesions and viral pneumonia for row were 
found. After admission, he was treated with anti-infection, antiviral and traditional Chinese medicine. On January 25, the novel coronavirus nucleic acid test from the Center for Disease Control and Prevention came back positive. The patient's wife was also confirmed positive in The Eighth People's Hospital of GZ. During the hospitalization, the patient continued to have low-to-moderate fever, progressive pulmonary inflammation and emotional symptoms, such as anxiety, irritable tendency and insomnia. After timely communication and treatment and adjustment of treatment plan, the patient improved and was discharged from the hospital on February 7.

Detailed patient's basic condition, clinical features and treatment methods are summarized as follows.

\begin{tabular}{|c|c|}
\hline Basic condition & $\begin{array}{l}\text { Male, } 37 \text { years old, married, from Guangzhou, Guangdong province, a company } \\
\text { employee }\end{array}$ \\
\hline Epidemiological & $\begin{array}{l}\text { General contact (colleague to colleague), his colleague had no obvious symptoms } \\
\text { of fever, and patient's wife presented with cough on the same day }\end{array}$ \\
\hline \multirow{3}{*}{$\begin{array}{l}\text { Specialized } \\
\text { examination }\end{array}$} & $\begin{array}{l}\mathrm{T}, 37.3^{\circ} \mathrm{C} ; \mathrm{P}, 104 \text { times/min; } \mathrm{R}, 18 \text { times } / \mathrm{min} \text {; and } \mathrm{BP}, 131 / 65 \mathrm{mmHg} \text {; sanity, } \\
\text { answered to the point; pharyngeal hyperaemia; slightly thick breath sounds in } \\
\text { both lungs; no obvious dry and wet rales. }\end{array}$ \\
\hline & $\begin{array}{l}\text { Results of blood test: WBC, } 4.59 \times 109 / \mathrm{L} \text {; PLT, } 136 \times 109 / \mathrm{L} \text {; NEUT, } 0.687 \text {; } \\
\text { LYMPH, and } 1 \times 109 / \mathrm{L} . \mathrm{Mp} \text {-ag and rsv-ag were negative and influenza antigen } \\
\text { a/b was also negative. }\end{array}$ \\
\hline & $\begin{array}{l}\text { Thoracic CT: Double pulmonary infectious lesions and viral pneumonia for row } \\
\text { were found. }\end{array}$ \\
\hline $\begin{array}{l}\text { Clinical signs } \\
\text { and symptoms }\end{array}$ & Fever and cough for 4 days \\
\hline \multirow{4}{*}{ Treatment } & $\begin{array}{l}\text { 1) Anti-infection and antiviral therapy: moxifloxacin hydrochloride, taxepoxil, } \\
\text { schupen; Abidor, Kridge, interferon A-2B atomized inhalation. }\end{array}$ \\
\hline & $\begin{array}{l}\text { 2) Symptomatic and supportive treatment: gamma globulin to improve } \\
\text { immunity, mucosolvan, asmei to relieve cough and expectum, and alprazolam to } \\
\text { fight anxiety. }\end{array}$ \\
\hline & $\begin{array}{l}\text { 3) TCM treatment: TCM experts consult and guide the TCM treatment of } \\
\text { pneumonia, such as cold-tea and granules of Lianhua Qingwen. }\end{array}$ \\
\hline & $\begin{array}{l}\text { 4) Psychological counseling: Consult psychological specialists, try to meet the } \\
\text { reasonable requirements of the patients, and ask the community to help solve } \\
\text { family problems. }\end{array}$ \\
\hline
\end{tabular}

\section{Psychological Problems and Measures}

\subsection{Anxiety and Fear}

In the early stage of the outbreak of anxiety and fear, due to many uncertain factors and the spread of various true and false information on the Internet, the people's sense of security dropped sharply. They were grounded at home for a long time, excessively worried about being infected themselves and their families and constantly recalled whether they had contact history. Given the lack of professional medical knowledge, excessive attention to their own health could be easily associated with any discomfort with COVID-19. They suspected that they were infected or lucky not to be infected or even doubt the official data on the 
outbreak; they were highly sensitive, alert and restless [3]. In the present case, the patient had a history of contact which someone who was diagnosed with COVID-19 before he was admitted to the hospital. Several days later, he and his wife developed symptoms, and the patient showed obvious anxiety when he was admitted to the hospital. Communication with the patient revealed that his anxiety and fear resulted from several aspects. The family factors included 1) waiting for nucleic acid test and not knowing whether he and his wife were infected and 2) the child is too young to be cared for at home. In the case that the couple is diagnosed, will the child be infected or quarantined? In terms of economic factors, in the early stage of the epidemic, the country did not clarify whether the medical expenses are free or partially self-paid. According to media reports, the cost of treating a patient with COVID-19 may range from tens of thousands to hundreds of thousands of RMB, which is unaffordable for the average working family in China. In terms of social factors, due to the lack of knowledge of COVID-19 coupled with some negative media reports and Internet information, some people talk about the new coronal changes, while some showed discrimination and were xenophobic against patients and their families. Understanding the patient's specific problems and targeted treatment could alleviate the anxiety. Firstly, an effective communication link was established. Patients were required to bring mobile phones upon admission to the hospital to help them join the WeChat group of medical staff in the isolation ward. The medical staffs were on duty online 24 hours a day. Patients were comforted and encouraged that COVID-19 could be treated and controlled, and most cases are mild. They must wait for nucleic acid test results for approximately 3 days. Breathing meditation, listening to soothing music and other measures could help patients relax. Secondly, the patients' community and the relevant departments should be contacted to make proper arrangements for the patients' children to relieve them of worries. The community must do the disinfection and screening of the community where the patients live to prevent further spread of the epidemic. People should keep abreast of the latest national policy on COVID-19 and timely feedback must be provided to patients.

\subsection{Depression}

This kind of mood easily occurs in suspected or confirmed infected patients, in the early days of the outbreak, it even existed among some first-line medical staff. Given the lack of medical knowledge, patients are overly pessimistic that humans could not overcome the virus. They are afraid of not have access to prompt treatment, lose confidence and enthusiasm in life. In particular, during the isolation treatment, some patients and their families even felt self-abasement and self-reproach, thinking that they made mistakes or failed to protect their families [4]. Here, the patient was informed on the day of diagnosis on January 25 that his wife was also diagnosed in the Eighth People's Hospital of GZ on the same day. At that time, the patient still had a high fever and mild shortness of 
breath. He said, "nurse, i feel terrible, am I going to die?" It's really hard for a family to have two people sick at the same time, at this stage, close attention was given to the patient's psychological dynamics. His wife and children were informed on the latest and reliable information. He was persuaded not to pay too much attention to the epidemic and some negative information. Increased rest, support and encouragement combined with some successful treatment cases were provided. Some reasonable daily requirements of patients were met.

\subsection{Irritability, Easily Provoked and Pessimism}

Due to isolation treatment or disease progression, patients are often anxious, afraid, irritable, easily provoked and pessimistic and may even show aggressive behaviour. In the early days of the epidemic, the number of patients increased and arranging a single room for each person was sometimes impossible due to lack of beds. In the present case, the patient was staying in a double room next to a diagnosed patient who snored loudly at night. The roommate had a low level of education and spoke a local language, making the communication difficult. Thus, the patient himself was a doctor of education, he had heavy ideological burden. The snoring disturbed his sleep. He was very irritable and wanted to beat him or knock himself out. The medical staffs were also very nervous at the beginning. In the early days of the epidemic, all kinds of things could happen. In case of accidents, isolation suits are required. Close attention was given to the patient, and medical workers helped to appease the mediation and relieve his bad mood. He was promised to adjust the room the next day and given drugs to relieve emotions and help him sleep when necessary. After counselling, the patient's mood gradually stabilized and he could sleep.

\subsection{Bigotry, I Did It My Way}

Faced with the severe epidemic situation, some patients lose their rational cognition and blindly believe they would not be infected with the virus. They feel the virus is very far away and even produce the mentality that has nothing to do with oneself. They even reject science and do not listen to others than persuasion, blind self-confidence, refused to cooperate with the epidemic prevention work. They do not take any protective measures and ignore their and others' safety. They have no sense of responsibility; some people listen to rumours and even hoard masks, food and other supplies, thereby causing or aggravating social panic [3] [5]. This kind of bad mentality must be prevented and contained. These bad emotions may be accompanied with insomnia, gastrointestinal discomfort, diarrhoea, loss of appetite, difficulty in breathing or suffocation and decline of resistance [3] [6]. According to the emotional theory of traditional Chinese medicine, psychological and physiological adverse reactions are closely related and they often affect each other. Therefore, every family and individual must timely resolve their adverse emotions, adjust their mood, maintain a good attitude and overcome the epidemic period smoothly [4]. Here, the patient's 
roommate is a typical case. He was very cooperative in the ward and wore a mask before he was diagnosed. After the diagnosis was released, he often ran in the hospital room without a mask. This behaviour may cause significant damage to others. Therefore, the country has issued relevant laws and regulations. Once such behaviour violates laws and regulations and constitutes a crime, they could act as a deterrent to these people. In the present case, the patient had good education and he could actively cooperate with the treatment after mediation. During the whole treatment period, he was well isolated in a single room and soon recovered and left the hospital.

\section{Conclusion}

The sudden outbreak of COVID-19 caught people off guard at first. In this special period of the global continuous anti-COVID-19 epidemic, when sudden public health events occur, all kinds of information are overwhelming, whether true or false. The public and individuals are more vulnerable to the epidemic mentality than before and more prone to various adverse emotions and psychological problems. Failure of the state and medical units to intervene in a timely and effective manner could have a negative effect on individual physical and mental health, epidemic prevention and control and social stability. Our country's prevention and control measures are active and effective. In terms of treatment methods, on the basis of anti-infection and anti-virus, a combination of Chinese and Western medicine is used for symptomatic treatment, at the same time, the country must also be aware of the importance of psychological care. In the early stage of the epidemic, major hospitals promptly formulated various free cloud psychological tests and countermeasures, several specialists and doctors were online 24 hours a day answering questions of the public and yoga therapy and other activities were provided. These actions played a vital role in promoting the timely and effective control of the whole epidemic and social stability. In this paper, we personally experience the change of the patient's psychological state by tracking the whole process of a COVID-19 infected patient from onset to recovery in detail and make the medical staff pay attention to the patient's psychological problems, and take active intervention measures in terms of psychological problems. The human race will eventually win in this epidemic as long as everyone could achieve early detection, early isolation, early treatment.

\section{Conflicts of Interest}

The authors declare no conflicts of interest regarding the publication of this paper.

\section{References}

[1] WHO (2021) WHO Coronavirus (COVID-19) Dashboard. https://covid19.who.int/

[2] Hu, B.J., Gao, X.D. and Han, L.X. (2020) Covid-19 Prevention and Control 100 Questions. 1st Edition, Shanghai Science and Technology Press, Shanghai, 4 p. 
[3] Chinese Medical Doctors Association (2020) Novel Coronavirus National Mental Health Protection Manual. Peking University Medical Press, Beijing, 9-18.

[4] Fu, X.Y., Zhang, X.X. and Zhao, Z.J. (2020) Based on the Modern Therapy of Traditional Chinese Medicine to Investigate Mental Adjustment Method of COVID-19 Epidemic Period. Chinese Journal of Experimental Traditional Medical, 26, 39-44.

[5] Wu, F. (2020) How to Carry Out Self-Psychological Adjustment in the Current Epidemic Situation. Journal of Health.

[6] Fan, F.M. (2003) Crisis Response and Crisis Psychological Intervention of SARS. Journal of Tsinghua University (Philosophy and Social Sciences Edition), 32-37. 